\title{
Neuropathy of metachromatic leucodystrophy
}

\author{
K. L. DE SILVA AND JOHN PEARCE \\ From the Combined Neurological Service, Hull Royal Infirmary
}

SUMMARY We describe two patients with metachromatic leucodystrophy who presented with peripheral neuropathy and had no evidence of central nervous system involvement at the time of presentation. Such an occurrence is not well recognized and the diagnosis is usually missed until the other features of the disease manifest themselves. Early recognition of this disease may become of practical importance from the point of view of therapy, judging from recent developments, and is also important from the point of view of genetic counselling. We suggest that cases of peripheral neuropathy in infancy and childhood, should be subjected to peripheral nerve biopsy when the aetiology is not obvious.

Although it is known that the peripheral nerves share in the pathological changes that occur in metachromatic leucodystrophy (Greenfield, 1933; Brain and Greenfield, 1950; Thieffry and Lyon, 1959; Hagberg, Sourander, and Thoren, 1962; Webster, 1962) and that these changes may manifest themselves clinically (Hagberg et al., 1962; Hagberg, 1963; Fullerton, 1964), it is not well recognized that peripheral neuropathy may sometimes be the presenting feature of this disease (Yuddell, Gomez, Lambert, and Dockerty, 1967; Tasker and Chutorian, 1969). The purpose of this paper is to report two such patients, seen in one regional unit over the four year period, 1967-71, who presented purely as cases of peripheral neuropathy. One of these (case 1) has been reported in detail earlier (Aziz and Pearce, 1968) and will be only briefly described here.

\section{CASE 1}

(HRI 19109). This child born to unrelated parents without any family history of neurological disease presented at the age of $1 \frac{1}{2}$ years, with a history of difficulty in walking of a few weeks' duration. There was a past history of recurrent attacks of upper respiratory tract infection. On examination at the age of 18 months she was mentally alert, there was a left sixth-nerve palsy, the arms were normal but the legs were hypotonic, with weakness of both proximal and distal muscles, and the reflexes were depressed. A lumbar puncture examination at the time showed cerebrospinal fluid (CSF) protein $180 \mathrm{mg} / 100 \mathrm{ml}$. without cells, and a negative Lange curve. In view of $-\vec{\omega}$ these clinical and biochemical findings a diagnos $\overline{6}$ of postinfective peripheral neuritis was made.

Electrophysiological studies were done at the stage (Dr. D. Taverner). The conduction velocity if the right lateral popliteal nerve was $15 \mathrm{~m} / \mathrm{sec}$. Elec $\mathbb{D}_{0}$ tromyographic studies were done on the right aro terior tibial and left extensor digitorum brevs muscles. There was discrete motor activity with. spontaneous fibrillation potentials in both these muscles, confirming denervation in the muscles of the legs.

She showed an apparent improvement on steroids and was discharged from hospital. She later began to deteriorate and after six months from the onset of the illness she had become helpless and unable to stand. There was no change in the sixth nerve palsy. $\overrightarrow{0}$ At this stage her hands were unsteady and she had a $\exists$ coarse tremor while feeding herself. She was mentally alert and would play with her brother.

On readmission 10 months after the onset of the illness her legs were for the first time found to be spastic and the knee jerks were pathologically brisk. The right plantar response was equivocal. During this admission she had a major epileptic attack. 8 Repeated examinations of urine did not show meta- $₹$ chromatic granules. A pneumoventriculogram com- 0 bined with brain biopsy was carried out. The size of the ventricles was normal, but there were excessive pools of air over the cortex.

During the next three months she became pro- $\tilde{N}$ gressively withdrawn and irritable, had repeated N attacks of major epileptic convulsions, and developed N progressive cortical blindness. The spasticity in the 
legs increased and she developed contractures of her lower limbs in extension. The arms also became spastic with contractures in flexion. Twelve months after the onset of the disease she died of a fulminating bronchopneumonia. Permission for necropsy was withheld.

BRAIN BIOPSY (Dr. D. G. F. Harriman) There was an excess of glial nuclei in the white matter. The cytoplasm of the oligodendroglia was distended. In frozen sections these cells were found to contain abundant metachromatic granules staining brown with both toluidine blue and crystal violet. The myelin stained metachromatically with crystal violet but not with toluidine blue.

\section{CASE 2}

(HR 162461). This child, born to Indian parents who were first cousins, was brought from Syria for admission to the Combined Neurological Service, Hull Royal Infirmary, at the age of 7 years 5 months. Four weeks after the onset of malaria at the age of 3 years she had developed marked weakness and clumsiness of the arms and legs. It was alleged that there was some initial improvement in the power and coordination of the limbs and that this had subsequently remained static. At the age of 6 years she had been admitted to a university hospital in Lebanon for this ailment. At that time the child is reported to have been mentally clear and intelligent. There had been flaccid weakness and wasting of all four limbs and some ataxia. Sensation is reported to have been intact and the plantar responses flexor. There had been no other abnormal neurological signs. The CSF had contained protein $140 \mathrm{mg} / 100 \mathrm{ml}$. with no cells. A diagnosis of the Guillain-Barré syndrome had been made. In the year before her present admission the mother gave a clear story of increasing impairment of mental function. The child could no longer read or write and her vocabulary had decreased. Having previously been clean in her habits, she had become incontinent of urine and faeces. The mother stated that her general health had remained good, but that at the present time she walked with some difficulty and was clumsy with her hands, which showed a periodic trembling. There was no known neurological illness in the family and two younger sibs were apparently normal.

On examination she was a pleasant docile child who was incontinent without concern. Her skull appeared normal. Fundi, visual fields, and cranial nerves were apparently normal. There was a resting striatal type of tremor in both arms, left more than right. There was an additional intention tremor of cerebellar type in both arms and legs. There was marked cogwheel rigidity at both shoulder joints, but little rigidity elsewhere in the limbs. There was diffuse wasting of the arms and legs, a little more marked distally. Sensory testing was unreliable. Tendon reflexes were depressed in the arms and absent in the legs, but the plantar reflexes were clearly extensor.

Routine investigations, including radiographs of skull and chest, full blood count, ESR, and urine analysis were normal. The CSF contained protein $112 \mathrm{mg} / 100 \mathrm{ml}$. with gamma globulin $14 \%$, sugar 65 $\mathrm{mg} / 100 \mathrm{ml}$. and 1 lymphocyte/cu. mm. Electroencephalogram (EEG) showed a basically immature record with a generalized slow-wave abnormality of 2 to $3 \mathrm{~Hz}$ and amplitude $100 \mu \mathrm{V}$, compatible with diffuse encephalopathy. Nerve conduction studies showed marked motor neuropathy, the motor conduction velocity in the left ulnar nerve being 21 $\mathrm{m} / \mathrm{sec}$ and that in the left lateral popliteal nerve being $15 \mathrm{~m} / \mathrm{sec}$. Pneumoencephalography revealed cortical atrophy in both parietal regions. Of four urine cytological examinations, metachromatic material was found on two occasions, as intracellular metachromatic granules (Fig. 1).

PERIPHERAL NERVE BIOPSY (Dr. D. G. F. Harriman) A frozen section of the nerve stained by cresyl fast

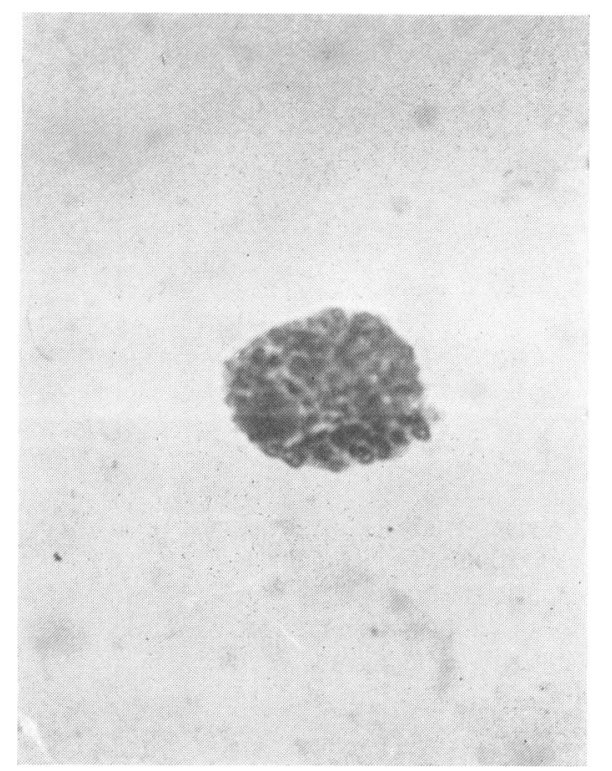

FIG. 1 Case 2. Epithelial cell in the urine showing intracellular metachromatic granules. 
violet (Fig. 2) revealed the deposition of conglomerates of brown metachromatic material between nerve fibres. The content of myelinated fibres was reduced and the myelin stained metachromatically over short lengths, probably close to Schwann cell nuclei.

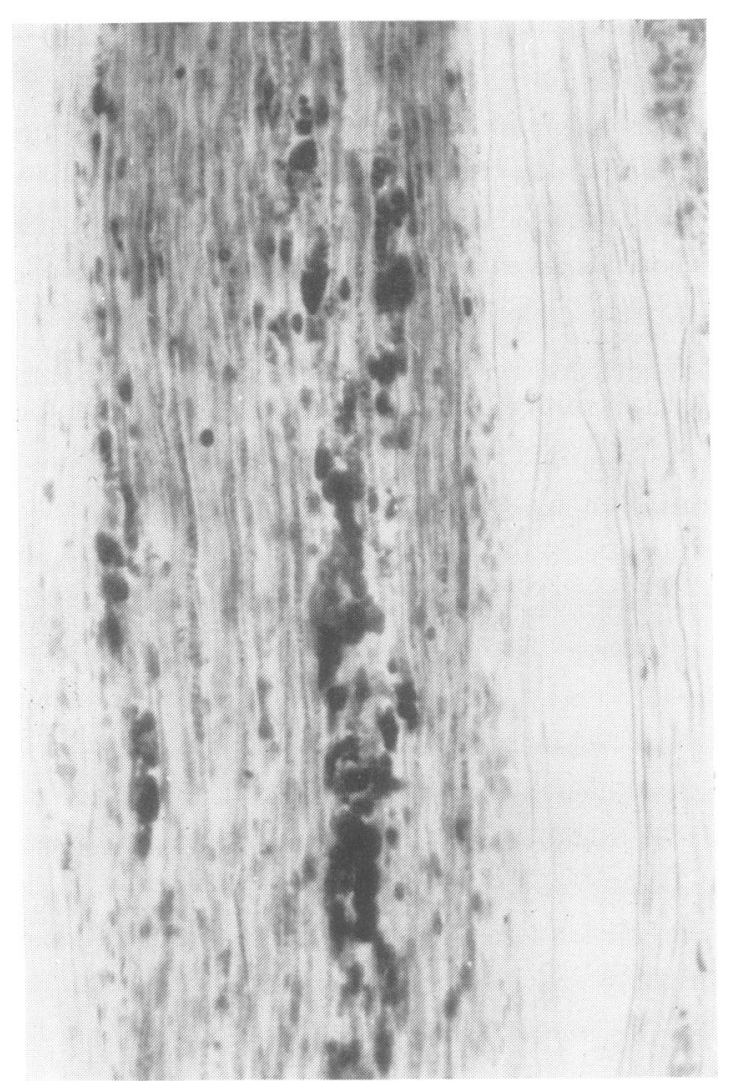

FIG. 2 Case 2. Frozen section of sural nerve stained by cresyl fast violet (see text).

The urine analysis and the nerve biopsy established the diagnosis.

The patient returned to Syria. Treatment with a vitamin A deficient diet (Moosa and Dubowitz, 1971 ) is being considered.

\section{DISCUSSION}

The accumulation of sulphatides, which characterizes metachromatic leucodystrophy, occurs not only in the central nervous system but in various other tissues including the peripheral nerves. The metachromatic granules accumulate predominantly in the Schwann cells (Webster, 1962). The degeneration of the myelin, which is formed by the Schwann cells, is presumably secondary to this.

Although the neurological manifestations of metachromatic leucodystrophy are mainly due to the central nervous system involvement, the peripheral nerve involvement also manifests itself clinically, and this fact has been largely overlooked. Although obtaining a history of sensory disturbance and carrying out objective sensory testing are often difficult in young children, the motor manifestations of peripheral neuropathy and hyporeflexia may be evident. This can be confirmed by electrophysiological studies. Fullerton (1964) reported a marked reduction of motor nerve conduction velocity in six of seven patients with metachromatic leucodystrophy.

Yudell et al. (1967) emphasized that meta chromatic leucodystrophy may present in thळ early phase of the disease as a pure polyneuro pathy. They reported two patients in whom this occurred. In the first the diagnosis was suspected only at the third visit of the patient and afteg pyramidal signs and other evidence of centrat nervous system involvement had developed. The्? second patient had presented elsewhere two years previously and the diagnosis had not been suspected. When first seen by the authors she had marked evidence of central nervous system involvement. In both cases the diagnosis was confirmed by sural nerve biopsy.

The fact that the diagnosis of this disease may be missed when it presents as a pure peripheral neuropathy is also illustrated by the present cases and by a recent paper on chronic polyneuritis of childhood (Tasker and Chutorian, 1969). Out of 17 cases that are described in that paper no aetiology could be defined in 15 , one was found to be due to metachromatic leucodystrophy, and one to Déjerine-Sottas disease. Their case of metachromatic leucodystrophy presented at the age of 28 months with a pure peripheral neuropathy, the cause of which could not then be established. The patient was readmitted on three further occasions without the diagnosis being established. It was only on his fifth and final admission at the age of 3 years and 
9 months, and after the development of obvious intellectual regression, nystagmus, a focal motor seizure, marked increase in muscle tone with scissoring of the legs, and bilateral Babinski responses that the possibility of metachromatic leucodystrophy was considered and confirmed by rectal biopsy and urinary testing. This diagnosis was further confirmed at necropsy 6 months later.

The biochemical basis of metachromatic leucodystrophy has recently been elucidated to a considerable extent and this may lead to the discovery of useful therapy. It is now known that in this disease there is an accumulation of sulphatides in the nervous system and other tissues due to a deficiency of the lysosomal enzyme, arylsulphatase A. Because vitamin A is necessary for one of the metabolic steps in the synthesis of sulphatide, a vitamin A deficient diet has been tried in the treatment of this disease and, although this apparently met with no success when first tried, a recent report (Moosa and Dubowitz, 1971) claims that this therapy appears to arrest the progression of the disease. The authors stress that failure in producing a useful result in the later stages of the disease is not surprising because the above therapy cannot reverse the damage already done, but can only prevent further damage. If the value of this therapy were to be confirmed early recognition of this disease would assume practical importance.

In view of the above and because early recognition of metachromatic leucodystrophy is also of practical importance for genetic counselling, every case of peripheral neuropathy in infancy and early childhood, which is an uncommon condition, deserves a peripheral nerve biopsy to exclude the possibility of this disease, unless the aetiology is obvious. Examination of epithelial cells in the urine and rectal biopsy for metachromatic material are less reliable diagnostic measures. Cerebral biopsy may be needed if other investigations are negative.

We wish to express our gratitude to Dr. D. G. F. Harriman for the neuropathological reports on both cases and to Dr. D. Taverner for his report on the electrophysiological studies in case 1 .

\section{REFERENCES}

Aziz, H., and Pearce, J. (1968). Peripheral neuropathy in metachromatic leucodystrophy. British Medical Journal, 4, 300.

Brain, W. R., and Greenfield, J. G. (1950). Late infantile metachromatic leuco-encephalopathy, with primary degeneration of the interfascicular oligodendroglia. Brain, 73, 291-317.

Fullerton, P. M. (1964). Peripheral nerve conduction in metachromatic leucodystrophy (sulphatide lipidosis). Journal of Neurology, Neurosurgery, and Psychiatry, 27, 100-105.

Greenfield, J. G. (1933). A form of progressive cerebral sclerosis in infants associated with primary degeneration of the interfascicular glia. Journal of Neurology and Psychopathology, 13, 289-302.

Hagberg, B., Sourander, P., and Thorén, L. (1962). Peripheral nerve changes in the diagnosis of metachromatic leucodystrophy. Acta Paediatrica (Uppsala), 51, Suppl. 135, 63-71.

Hagberg, B. (1963). Clinical symptoms, signs and tests in metachromatic leucodystrophy. In Brain Lipids and Lipoproteins, and the Leucodystrophies. Proceedings of the Neurochemistry Symposium, VII International Congress of Neurology, Rome, 1961. Pp. 134-146. Edited by J. Folch-Pi, and H. Bauer. Elsevier: Amsterdam.

Moosa, A., and Dubowitz, V. (1971). Late infantile metachromatic leucodystrophy. Effect of low vitamin A diet. Archives of Disease in Childhood, 46, 381-383.

Thieffry, S., and Lyon, G. (1959). Diagnostic d'un cas de leucodystrophie métachromatique (type Scholz) par la biopsie d'un nerf périphérique. Revue Neurologique, 100, $452-456$.

Tasker, W., and Chutorian, A. M. (1969). Chronic polyneuritis of childhood. Journal of Pediatrics, 74, 699-708.

Webster, H. deF. (1962). Schwann cell alterations in metachromatic leucodystrophy: Preliminary phase and electron microscopic observations. Journal of Neuropathology and Experimental Neurology, 21, 534-554.

Yudell, A., Gomez, M. R., Lambert, E. H., and Dockerty, M. B. (1967). The neuropathy of sulfatide lipidosis (metachromatic leukodystrophy). Neurology (Minneap.), 17, 103111 and 127. 